\title{
Solution of Optimal Reactive Power Dispatch by Flower Pollination Algorithm
}

\author{
D. Vigneswaran ${ }^{1}$, R. Sugumar ${ }^{2}$, S. Vijayaraj ${ }^{3}$ \\ Professor, Dept of EEE, Maha Bharathi Engineering College, Salem, Tamil Nadu, India ${ }^{1}$ \\ PG Student, Dept of EEE, Maha Bharathi Engineering College, Salem, Tamil Nadu, India ${ }^{2}$ \\ Assistant Professor, Dept of EEE, KCET, Cuddalore, Tamil Nadu, India ${ }^{3}$
}

\begin{abstract}
This study presents an efficient and reliable evolutionary-based approach, termed as Flower Pollination Algorithm (FPA), to solve the optimal reactive power dispatch (ORPD) problem of power system. The performance of the proposed FPA is examined and tested, successfully, on standard IEEE-30 test power systems for the solution of ORPD problem in which control of bus voltages, tap position of transformers and reactive power sources are involved. The objective function considered is either minimisation of active power transmission loss or that of total voltage deviation or enhancement of voltage stability index. The results offered by the proposed FPA are compared with those offered by other evolutionary optimisation techniques surfaced in the recent state-of-the-art literature. Simulation results indicate that the proposed FPA yields superior solution over the other recently surfaced popular techniques in terms of effectiveness and convergence speed.
\end{abstract}

Keywords: Reactive Power Dispatch, Flower Pollination Algorithm, Loss minimization.

\section{INTRODUCTION}

Optimal reactive power dispatch problem is one of the difficult optimization problems in power systems. The sources of the reactive power are the generators, synchronous condensers, capacitors, static compensators and tap changing transformers. The problem that has to be solved in a reactive power optimization is to determine the required reactive generation at various locations so as to optimize the objective function. Here the reactive power dispatch problem involves best utilization of the existing generator bus voltage magnitudes, transformer tap setting and the output of reactive power sources so as to minimize the loss and to enhance the voltage stability of the system. It involves a non linear optimization problem. Various mathematical techniques have been adopted to solve this optimal reactive power dispatch problem. These include the gradient method [1-2], Newton method [3] and linear programming [4-7].The gradient and Newton methods suffer from the difficulty in handling inequality constraints. To apply linear programming, the input- output function is to be expressed as a set of linear functions which may lead to loss of accuracy. Recently global optimization techniques such as genetic algorithms have been proposed to solve the reactive power flow problem $[8,9]$. A genetic algorithm is a stochastic search technique based on the mechanics of natural selection. In this paper, genetic algorithm is used to solve the voltage constrained reactive power dispatch problem. The proposed algorithm identifies the optimal values of generation bus voltage magnitudes, transformer tap setting and the output of the reactive power sources so as to minimize the transmission loss and to improve the voltage stability. The effectiveness of the proposed approach is demonstrated through IEEE-30 bus system. The test results show the proposed algorithm gives better results with less computational burden and is fairly consistent in reaching the near optimal solution [10]. In this paper, FPA is applied for achieving enhanced computational speed and improved convergence profile of ORPD problem on standard IEEE-30 bus power system. The simulation results yielded by the proposed FPA technique are compared with those offered by the other computational intelligence-based techniques.

\section{PROBLEM FORMULATION}

ORPD problem is, mainly, concerned with either minimisation of PLoss or that of TVD or improvement of VSI, satisfying various equality and inequality constraints.

Minimisation of $\mathbf{P}_{\text {loss: }}$ :

The general formulation of Ploss minimisation problem may be expressed as follows:

$$
\operatorname{minimize} \mathrm{J}_{1}\left(\mathrm{x}_{1}, \mathrm{x}_{2}\right)=\operatorname{minimize} \mathrm{P}_{\text {loss }} \sum_{\mathrm{K}=1}^{\mathrm{NL}}\left[\mathrm{G}_{\mathrm{k}}\left(\mathrm{V}_{\mathrm{p}}^{2}+\mathrm{V}_{\mathrm{q}}^{2}-2 \mathrm{~V}_{\mathrm{p}} \mathrm{V}_{\mathrm{q}} \cos \delta_{\mathrm{pq}}\right)\right]
$$


subject to

$$
\left\{\begin{array}{l}
g\left(X_{1}, X_{2}=0\right) \\
h\left(X_{1}, X_{2} \leq 0\right)
\end{array}\right\}
$$

where $\mathrm{J}_{1}\left(\mathrm{x}_{1}, \mathrm{x}_{2}\right)$ is the active power transmission loss minimisation function, $\mathrm{X}_{1}$ is the vector of dependent variables consisting of load voltages $\left(\mathrm{V}_{\mathrm{L} 1}, \ldots, \mathrm{V}_{\mathrm{LN}} \mathrm{PQ}\right)$ generators' reactive powers $\left(\mathrm{Q}_{\mathrm{G} 1}, \ldots, \mathrm{Q}_{\mathrm{GN}} \mathrm{PV}\right)$ and transmission line loadings $\left(\mathrm{S}_{\mathrm{L} 1}, \ldots, \mathrm{V}_{\mathrm{LN}_{\mathrm{L}}}\right) \mathrm{X}_{2}$ is the vector of control variables consisting of generators' voltages $\left(\mathrm{V}_{\mathrm{G} 1}, \ldots, \mathrm{V}_{\mathrm{GN}}\right)$ transformers' tap settings $\left(\mathrm{T}_{1}, \ldots, \mathrm{T}_{\mathrm{N}_{\mathrm{T}}}\right)$ and reactive power injections $\left(\mathrm{Q}_{\mathrm{C} 1}, \ldots, \mathrm{Q}_{\mathrm{CN}_{\mathrm{C}}}\right), \mathrm{G}_{\mathrm{k}}$ is the conductance of branch $\mathrm{k}, \mathrm{V}_{\mathrm{p}}, \mathrm{V}_{\mathrm{q}}$ are voltages of the $\mathrm{p}_{\mathrm{th}}$ and the $\mathrm{q}_{\mathrm{th}}$ buses, respectively and $\delta_{\mathrm{pq}}$ is the voltage angle difference between buses $\mathrm{p}$ and $\mathrm{q}$. Therefore $\mathrm{X}_{1}$ and $\mathrm{X}_{2}$ may be expressed as

$$
\begin{aligned}
& \mathrm{X}_{1}=\left[\mathrm{V}_{\mathrm{L} 1}, \ldots \ldots \mathrm{V}_{\mathrm{LN}}, \mathrm{Q}_{\mathrm{G} 1, \ldots \ldots . . \mathrm{Q}_{\mathrm{GN}} \mathrm{PV}}, \mathrm{S}_{\mathrm{L} 1 \ldots \ldots . .} \mathrm{S}_{\mathrm{LN}_{\mathrm{L}}}\right. \\
& \mathrm{X}_{2}=\left[\mathrm{V}_{\mathrm{G} 1, \ldots \ldots .} \mathrm{V}_{\mathrm{GN}}, \mathrm{T}_{1, \ldots \ldots} \mathrm{T}_{\mathrm{N}_{\mathrm{T}}}, \mathrm{Q}_{\mathrm{C} 1 \ldots \ldots . . .} \mathrm{Q}_{\mathrm{CN}_{\mathrm{C}}}\right]
\end{aligned}
$$

where $\mathrm{N}_{\mathrm{PV}}$ is the number of generator buses, $\mathrm{N}_{\mathrm{PQ}}$ is the number of load buses, $\mathrm{N}_{\mathrm{L}}$ is the number of transmission lines, $\mathrm{N}_{\mathrm{T}}$ is the number of tap setting transformer branches and $\mathrm{N}_{\mathrm{C}}$ is the number of capacitor banks.

\section{Minimisation of TVD:}

The general formulation of TVD minimisation objective may be stated as in (5)

$$
\text { minimize } \mathrm{J}_{2}\left(\mathrm{x}_{1}, \mathrm{x}_{2}\right)=\operatorname{minimize} \mathrm{TVD}=\sum_{\mathrm{P}=1}^{\mathrm{N}_{\mathrm{PQ}}}\left|\mathrm{V}_{\mathrm{P}-} \mathrm{V}_{\mathrm{P}}^{\mathrm{ref}}\right|
$$

where $J_{2}(x 1, x 2)$ is the TVD minimisation objective function, $V_{p}$ is the voltage at bus $p$ and $V_{P}^{\text {ref }}$ is the desired value of the voltage magnitude of the $\mathrm{p}_{\text {th }}$ bus, taken as $1 \mathrm{pu}$.

\section{Improvement of VSI:}

The general objective of VSI improvement problem may be stated as in (6)

Minimise $\mathrm{J}_{3}\left(\mathrm{X}_{1}, \mathrm{X}_{2}\right)=\operatorname{Minimise}\left(\mathrm{L}_{\max }\right)$

$$
=\min [\max (\mathrm{LK})], \quad \mathrm{K}=1,2 \quad \mathrm{~N} \mathrm{P} \mathrm{Q}
$$

where Lk is the voltage stability indicator (L-index) of the kth node. The value of Lk may be written as

$$
\mathrm{L}_{\mathrm{k}}=\left|1-\sum_{\mathrm{P}=1}^{\mathrm{NPV}} \mathrm{m}_{\mathrm{qp}} \frac{\mathrm{Vp}}{\mathrm{Vq}}<\left\{\lambda \mathrm{pq}+\left(\theta_{\mathrm{p}}-\theta_{\mathrm{q}}\right)\right\}\right|
$$

where Mqp are the (p, q)th components of the sub-matrices obtained from partial inversion of $\mathrm{Y}_{\text {bus }}$ matrix. The value of $\mathrm{M}_{\mathrm{qp}}$ is given by (8)

$$
\mathrm{M}_{\mathrm{qp}}=-\left[\mathrm{Y}_{\mathrm{qq}}\right]^{-1}\left[\mathrm{Y}_{\mathrm{qp}}\right]
$$

where $\lambda \mathrm{pq}$ is the phase angle of $\mathrm{M}_{\mathrm{qp}}, \theta_{\mathrm{p}}, \theta_{\mathrm{q}}$ are phase angles of the pth and the qth bus voltages, respectively, $\mathrm{Y}_{\mathrm{qq}}$ is the self-admittance term of the qth bus and $\mathrm{Y}_{\mathrm{qp}}$ is the mutual admittance between the qth and pth buses.

Equality constraints:

constraints representing the load flow equations given by (9)

$$
\left\{\begin{array}{l}
\mathrm{P}_{\mathrm{G}_{\mathrm{P}}}-\mathrm{P}_{\mathrm{L}_{\mathrm{P}}}=\sum_{\mathrm{q}=1}^{\mathrm{NB}} \mathrm{V}_{\mathrm{p}} \| \mathrm{V}_{\mathrm{q}}\left(\mathrm{G}_{\mathrm{pq}} \cos \delta_{\mathrm{pq}}+\mathrm{B}_{\mathrm{Pq}} \sin \delta_{\mathrm{pq}}\right) \\
\mathrm{Q}_{\mathrm{G}_{\mathrm{P}}}-\mathrm{Q}_{\mathrm{L}_{\mathrm{P}}}=\sum_{\mathrm{q}=1}^{\mathrm{NB}} \mathrm{Vp} \| \mathrm{Vq}\left(\mathrm{G}_{\mathrm{pq}} \sin \delta_{\mathrm{pq}}-\mathrm{B}_{\mathrm{pq}} \cos \delta_{\mathrm{pq}}\right.
\end{array}\right.
$$

where PGp, QGp are injected active and reactive powers, at the pth bus, respectively, PLp, QLp are active and reactive power demands, at the pth bus, respectively, Gpq, Bpq are transfer conductance and susceptance, between the pth and the qth buses, respectively and NB is the number of buses. 


\section{ISO 3297:2007 Certified}

Vol. 5, Issue 6, June 2017

Inequality constraints:

i. Generator constraints:

For all the generator voltages (including slack bus), real and reactive power outputs (including slack bus) must be restricted within their lower and upper limits as stated in (10)

$$
\left\{\begin{array}{l}
V_{G_{P}}^{M i n} \leq V_{G_{P}} \leq V_{G_{P}}^{M a x}, p=1,2, \ldots \ldots N_{P V} \\
V_{G_{P}}^{\min } \leq Q_{G_{P}} \leq Q_{G_{P}}^{\max }, P=1,2 \ldots \ldots \ldots N_{P V}
\end{array}\right.
$$

\section{ii. Transformer constraints:}

Transformer tap settings must be within their specified lower and upper limits as presented in (11)

$$
T_{G_{P}}^{\min } \leq Q_{G_{P}} \leq Q_{G_{P}}^{\max }, p=1,2 \ldots \ldots N_{T}
$$

\section{iii. Shunt VAR compensator constraints:}

Reactive power outputs of shunt VAR compensators must be restricted within their lower and upper limits as written in (12)

$Q_{C_{P}}^{\min } \leq Q_{C_{P}} \leq Q_{C_{P}}^{\max } p=1,2 \ldots \ldots N_{C}$

\section{iv. Security constraints:}

These include the constraints on voltages at load buses and transmission line loadings. Each of these constraints must be within their lower and upper operating limits, as expressed in (13) and (14), respectively

$$
\begin{aligned}
V_{L_{P}}^{\min } \leq V_{L_{P}} \leq V_{L_{P}}^{\max }, p=1,2 \ldots \ldots, N_{P Q} \\
\mathrm{~S}_{\mathrm{L}_{\mathrm{P}}} \leq \mathrm{S}_{\mathrm{L}_{\mathrm{P}}}^{\max }, \mathrm{p}=1,2 \ldots \ldots \ldots \mathrm{N}_{\mathrm{L}}
\end{aligned}
$$

\section{NATURE-INSPIRED FLOWER POLLINATION ALGORITHM}

The flower reproduction is ultimately through pollination. Flower pollination is connected with the transfer of pollen, and such transfer of pollen is related with pollinators such as insects, birds, animals etc. some type of flowers depend only on specific type of insects or birds for successful pollination. Two main forms of pollination are A-biotic and biotic pollination. $90 \%$ of flowering plants are belonging to biotic pollination process. That is, the way of transferring the pollen through insects and animals. $10 \%$ of pollination takes A-biotic method, which doesn't need any pollinators. Through Wind and diffusion help pollination of such flowering plants and a good example of A-biotic pollination is Grass [10, 11]. A good example of pollinator is Honey bees, and they have also developed the so-called flower constancy. These pollinators tend to visit exclusively only certain flower species and bypass other flower species. Such type of flower reliability may have evolutionary advantages because this will maximize the transfer of flower pollen .Such type of flower constancy may be advantageous for pollinators also, because they will be sure that nectar supply is available with their some degree of memory and minimum cost of learning, switching or exploring. Rather than focusing on some random, but potentially more satisfying on new flower species, and flower dependability may require minimum investment cost and more likely definite intake of nectar [12]. In the world of flowering plants, pollination can be achieved by self-pollination or crosspollination. Cross-pollination means the pollination can occur from pollen of a flower of a different plant, and self-pollination is the fertilization of one flower, such as peach flowers, from pollen of the same flower or different flowers of the same plant, which often occurs when there is no dependable pollinator existing.

Biotic, crosspollination may occur at long distance, by the pollinators like bees, bats, birds and flies can fly a long distance. Bees and Birds may behave as Levy flight behaviour [13], with jump or fly distance steps obeying a Levy allotment. Flower fidelity can be considered as an increment step using the resemblance or difference of two flowers. The biological evolution point of view, the objective of the flower pollination is the survival of the fittest and the optimal reproduction of plants in terms of numbers as well as the largely fittest. The flower reproduction is done through pollination process. Flower pollination is connected with the relocation of pollen and such transfer of pollen is related with pollinators such as insects, birds, animals etc.

The major two pollination are A-biotic and biotic pollination. $90 \%$ of flowering plants are belonging to biotic pollination process. That is, the way of transferring the pollen through insects and animals. 10\% of pollination takes Abiotic method, which doesn't need any pollinators. . Through Wind and diffusion help pollination of such flowering plants and a good example of A-biotic pollination is Grass. A very good example of pollinator is Honey bees, and they have also developed the so-called flower constancy. These pollinators tend to visit exclusively only certain flower species and bypass other flower species. Such type of flower reliability may have evolutionary advantages because this will maximize the transfer of flower pollen. 
UGC Approved Journal

IJIREEICE

\section{International Journal of Innovative Research in} Electrical, Electronics, Instrumentation and Control Engineering

\section{ISO 3297:2007 Certified}

Vol. 5, Issue 6, June 2017

\section{A. Rules For Flower Pollination Algorithm.}

1. Biotic and cross-pollination is considered as global pollination process with pollen- carrying pollinators performing Levy flights.

2. Abiotic and self-pollination are considered as local pollination.

3. Flower constancy can be considered as the reproduction probability is proportional to the similarity of two flowers involved.

4. Local pollination and global pollination is controlled by a switch probability $\mathrm{Pa} \in[0,1]$. Due to the physical proximity and other factors such as wind, local pollination can have a significant fraction pa in the overall pollination activities.

\section{B. Mathematical representation of Flower Pollination Algorithm.}

The first rule plus flower constancy can be represented mathematically as

$$
\mathrm{x}_{\mathrm{i}}^{\mathrm{t}+1}=\mathrm{X}_{\mathrm{i}}^{\mathrm{t}}+\mathrm{L}\left(\mathrm{X}_{\mathrm{i}}^{\mathrm{t}}-\mathrm{g}_{*}\right)
$$

where $\mathrm{X}_{\mathrm{i}}^{\mathrm{t}}$ is the pollen $\mathrm{i}$ or solution vector $\mathrm{X}_{\mathrm{i}}$ at iteration $\mathrm{t}$, and $\mathrm{g}_{*}$ is the current best solution found among all solutions at the current generation/iteration.

Levy distribution is given by

$$
\mathrm{L} \sim \frac{\lambda \Gamma \sin \left(\frac{\pi \lambda}{2}\right)}{\pi} \frac{1}{\mathrm{~S}^{1+\lambda}},\left(\mathrm{S} \gg \mathrm{S}_{0}>0\right)
$$

where $\mathrm{L}$ is the strength of the pollination should be greater than zero, $\Gamma(\lambda)$ is the gamma function and this distribution is valid for large steps $\mathrm{s}>0$.

The local pollination can be represented as

$$
\mathrm{x}_{\mathrm{i}}^{\mathrm{t}+1}=\mathrm{X}_{\mathrm{i}}^{\mathrm{t}}+\varepsilon\left(\mathrm{X}_{\mathrm{j}}^{\mathrm{t}}-\mathrm{X}_{\mathrm{k}}^{\mathrm{t}}\right)
$$

where, $X_{j}^{t}$ and $X_{k}^{t}$ are pollens from the different flowers of the same plant species. This essentially mimic the flower constancy in a limited neighbourhood. Mathematically, if $\mathrm{X}_{\mathrm{j}}^{\mathrm{t}}$ and $\mathrm{X}_{\mathrm{k}}^{\mathrm{t}}$ comes from the same species or selected from the same population, this become a local random walk if we draw from a uniform distribution in $[0,1]$.

\section{Switch probability or proximity probability (pa).}

Most flower pollination activities can occur at both local and global scale. In practice, adjacent flower patches or flowers in the not-so-far-away neighbourhood are more likely to be pollinated by local flower pollens that those far away. For this, we use a switch probability (Rule 4) or proximity probability pa to switch between common global pollination to intensive local pollination. in this simulation we used $\mathrm{pa}=0.6$ and $\mathrm{pa}=0.8$ to analyse the simulation result.

\section{Pseudo code of Flower Pollination Algorithm (FPA).}

Objective min or $\max \mathrm{f}(\mathrm{x}), \mathrm{x}=\left(\mathrm{x}_{1}, \mathrm{x}_{2}, \ldots, \mathrm{x}_{\mathrm{d}}\right)$

Initialize a population of $\mathrm{n}$ flowers/pollen gametes with random solutions

Find the best solution $\mathrm{g}_{*}$ in the initial population

Define a switch probability $\mathrm{Pa} \in[0,1]$.

while ( $\mathrm{t}<$ MaxGeneration)

for $\mathrm{i}=1: \mathrm{n}$ (all $\mathrm{n}$ flowers in the population)

if rand $<$ pa,

Draw a (d-dimensional) step vector $L$ which obeys a Levy distribution

Global pollination via $\mathrm{X}_{\mathrm{i}}^{\mathrm{t}+1}=\mathrm{X}_{\mathrm{i}}^{\mathrm{t}}+\mathrm{L}\left(\mathrm{X}_{\mathrm{i}}^{\mathrm{t}}-\mathrm{g}_{*}\right)$

else

Draw $\varepsilon$ from a uniform distribution in $[0,1]$

Randomly choose $\mathrm{j}$ and $\mathrm{k}$ among all the solutions

Do local pollination via $\mathrm{X}_{\mathrm{i}}^{\mathrm{t}+1}=\mathrm{X}_{\mathrm{i}}^{\mathrm{t}}+\varepsilon\left(\mathrm{X}_{\mathrm{j}}^{\mathrm{t}}-\mathrm{X}_{\mathrm{k}}^{\mathrm{t}}\right)$

end if

Evaluate new solutions

If new solutions are better, update them in the population

end for

Find the current best solution $\mathrm{g}_{*}$

end while. 
UGC Approved Journal

IJIREEICE

International Journal of Innovative Research in Electrical, Electronics, Instrumentation and Control Engineering

ISO 3297:2007 Certified

Vol. 5, Issue 6, June 2017

\section{SIMULATION RESULTS}

FPA based results of the ORPD problem for Ploss, TVD and L-index minimisation objective of this test system is presented in Table 1. These results are compared with those offered by the algorithms such as KHA and CKHA.

Table.1.Best control variable settings for power loss, TVD and L-index minimisation.

\begin{tabular}{|c|c|c|c|c|c|}
\hline $\begin{array}{c}\text { Control } \\
\text { variables }\end{array}$ & $\begin{array}{c}\text { KHA } \\
{[18]}\end{array}$ & $\begin{array}{c}\text { CKHA } \\
{[18]}\end{array}$ & $\begin{array}{l}\text { Proposed FPA For } \\
\text { Loss Minimization }\end{array}$ & $\begin{array}{l}\text { Proposed FPA For } \\
\text { TVD Minimization }\end{array}$ & $\begin{array}{l}\text { Proposed FPA For L- } \\
\text { index Minimization }\end{array}$ \\
\hline $\mathrm{V}_{\mathrm{G} 1}$ & 1.05 & 1.05 & 1.05 & 1.05 & 1.05 \\
\hline $\mathbf{V}_{\mathrm{G} 2}$ & 1.0381 & 1.0473 & 1.0278 & 1.0256 & 1.02389 \\
\hline$V_{G 5}$ & 1.011 & 1.0293 & 1.0293 & 1.0238 & 1.0229 \\
\hline $\mathbf{V}_{\mathrm{G} 8}$ & 1.025 & 1.035 & 1.028 & 1.016 & 1.012 \\
\hline$V_{G 11}$ & 1.05 & 1.05 & 1.05 & 1.05 & 1.05 \\
\hline$V_{G 13}$ & 1.05 & 1.05 & 1.05 & 1.05 & 1.05 \\
\hline $\mathbf{T}_{11}$ & 0.9541 & 0.9916 & 0.9686 & 0.9548 & 0.9489 \\
\hline $\mathbf{T}_{12}$ & 1.0412 & 0.9538 & 1.9538 & 1.9486 & 1.9369 \\
\hline $\mathbf{T}_{15}$ & 0.9514 & 0.9603 & 0.9331 & 0.9327 & 0.9347 \\
\hline $\mathbf{T}_{36}$ & 0.9541 & 0.967 & 0.948 & 0.948 & 0.946 \\
\hline $\mathbf{Q C}_{\mathbf{1 0}}$ & 0.0089 & 0.0092 & 0.0092 & 0.0091 & 0.0097 \\
\hline $\mathbf{Q C}_{12}$ & 0 & 0 & 0 & 0 & 0 \\
\hline $\mathbf{Q C}_{15}$ & 0.0141 & 0.0153 & 0.0148 & 0.0139 & 0.0127 \\
\hline $\mathrm{QC}_{17}$ & 0.04989 & 0.0497 & 0.0495 & 0.0492 & 0.0492 \\
\hline $\mathbf{Q C}_{20}$ & 0.0314 & 0.0302 & 0.0301 & 0.03 & 0.03 \\
\hline $\mathbf{Q C}_{21}$ & 0.0345 & 0.05 & 0.045 & 0.043 & 0.041 \\
\hline $\mathbf{Q C}_{23}$ & 0.0241 & 0.0134 & 0.0234 & 0.0231 & 0.0238 \\
\hline $\mathrm{QC}_{24}$ & 0.05 & 0.05 & 0.05 & 0.05 & 0.05 \\
\hline $\mathbf{Q C}_{29}$ & 0.0107 & 0.0121 & 0.0111 & 0.0118 & 0.0116 \\
\hline Ploss, MW & 3.65 & 3.24 & 3.21 & 3.52 & 3.71 \\
\hline TVD, pu & 1.3415 & 1.3364 & 1.3856 & 1.3256 & 1.3589 \\
\hline L-index, pu & 0.1425 & 0.1402 & 0.1416 & 0.1427 & 0.1389 \\
\hline
\end{tabular}
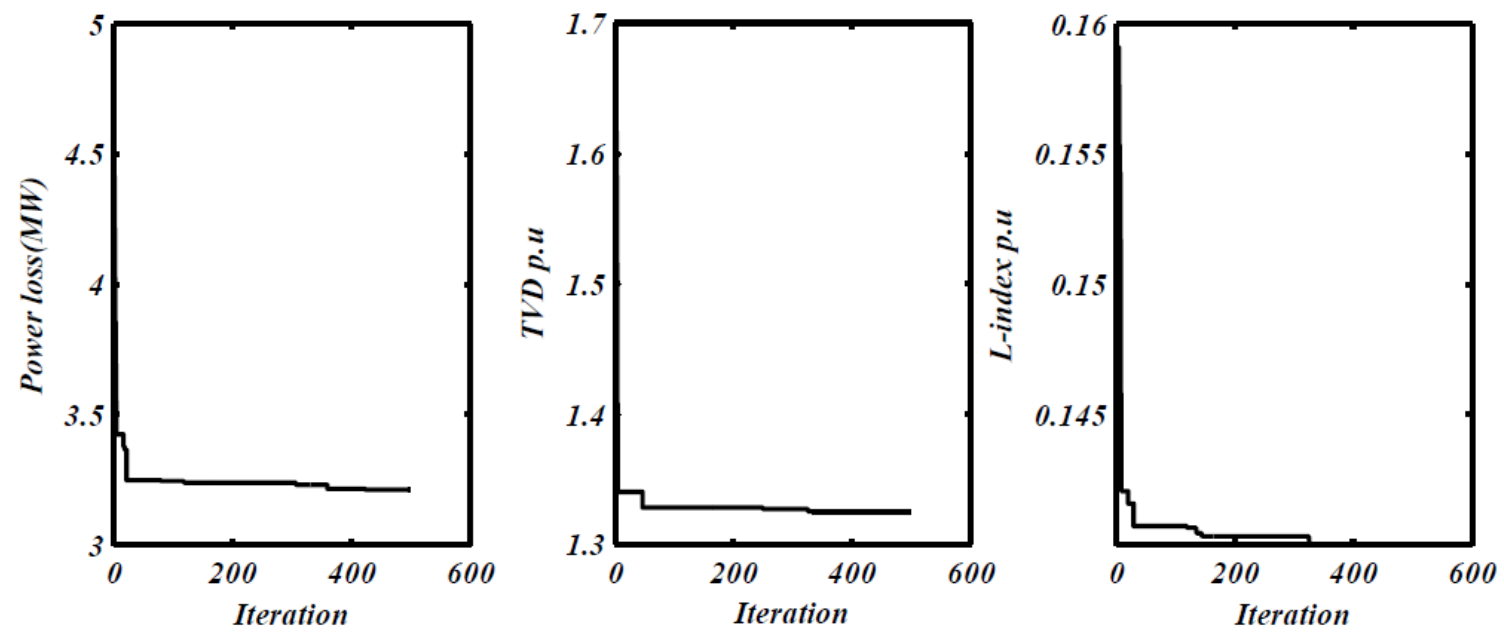

Figure.1.Convergence characteristics of loss, TVD and L-index minimization

\section{CONCLUSION}

In this paper, FPA is proposed to solve the ORPD problem of power system having varying degree of dimensions and complexities. To check the superiority of the proposed FPA, it is tested on standard IEEE-30 bus power system. Simulation results, as offered by the proposed FPA is compared with other popular techniques recently reported in the recent state-of-the-art literatures and it is proved that this method having better efficiency, flexibility and good stability. 
UGC Approved Journal

IJIREEICE

\section{REFERENCES}

[1] O.Alsac,and B. Scott, "Optimal load flow with steady state security”, IEEE Transaction. PAS -1973, pp. 745-751.

[2] Lee K Y ,Paru Y M , Oritz J L -A united approach to optimal real and reactive power dispatch, IEEE Transactions on power Apparatus and systems 1985: PAS-104: 1147-1153

[3] A.Monticelli , M .V.F Pereira , and S. Granville, "Security constrained optimal power flow with post contingency corrective rescheduling", IEEE Transactions on Power Systems :PWRS-2, No. 1, pp.175-182.,1987.

[4] Deeb N ,Shahidehpur S.M ,Linear reactive power optimization in a large power network using the decomposition approach. IEEE Transactions on power system 1990: 5(2): 428-435

[5] E. Hobson ,'Network consrained reactive power control using linear programming, ' IEEE Transactions on power systems PAS -99 (4) ,pp $868=877,1980$

[6] K.Y Lee ,Y.M Park, and J.L Oritz, "Fuel -cost optimization for both real and reactive power dispatches" , IEE Proc; 131C,(3), pp.85-93.

[7] M.K. Mangoli, and K.Y. Lee, "Optimal real and reactive power control using linear programming" , Electr.Power Syst.Res, Vol.26, pp.1$10,1993$.

[8] S.R.Paranjothi , and K.Anburaja, “Optimal power flow using refined genetic algorithm”, Electr.Power Compon.Syst, Vol. 30, $1055-1063,2002$.

[9] D. Devaraj, and B. Yeganarayana, "Genetic algorithm based optimal power flow for security enhancement", IEE proc-Generation.Transmission and. Distribution; 152, 6 November 2005

[10] D.Devaraj ,' Improved genetic algorithm for multi - objective reactive power dispatch problem' European Transactions on electrical power 2007 ; 17: 569-581

[11] C.A. Canizares , A.C.Z.de Souza and V.H. Quintana , "Comparison of performance indices for detection of proximity to voltage collapse ," vol. 11. no.3, pp.1441-1450, Aug 1996

[12] B.Gao ,G.K Morison P.Kundur ,'voltage stability evaluation using modal analysis ‘ Transactions on Power Systems ,Vol 7 , No .4 ,November 1992.

[13] D Goldberg, "Genetic algorithms in search, optimization and machine learning", Addison-Wesley,1989.

[14] -Deb,K.(201):Multi-objective optimization using evolutionary algorithms 1st ed.(John Wiley \&Sons,Ltd.).

[15] - Eshelman.L.J and Schaffer;J.D.(193): Real coded genetic algorithms and interval schemata. In: foundations of Genetic Algorithms 2 , Ed.L.Darrell Whitely (Morgan Kaugmann),PP 187-202

[16] Wu Q H, Ma J T. Power system optimal reactive power dispatch using evolutionary programming. IEEE Transactions on power systems 1995; 10(3): 1243-1248

[17] S.Durairaj, D.Devaraj, P.S.Kannan ,'Genetic algorithm applications to optimal reactive power dispatch with voltage stability enhancement' IE(I) Journal-EL Vol 87,September 2006.

[18] Aparajita Mukherjee, Vivekananda Mukherjee, " Solution of optimal reactive power dispatch by chaotic krill herd algorithm", IET Gener. Transm. Distrib., 2015, Vol. 9, Iss. 15, pp. 2351-2362 